\title{
Do Spatial Price Indices Reshuffle the Italian Income Distribution?
}

\author{
M. Grazia Pittau, Roberto Zelli, Riccardo Massari \\ Sapienza University of Rome, P.le ALdo Moro 5, Rome, Italy \\ E-mail: \{grazia.pittau, roberto.zelli, riccardo.massari\}@uniroma1.it \\ Received February 24, 2011; revised April 6, 2011; accepted April 20, 2011
}

\begin{abstract}
This paper examines how spatial price differentials affect income distribution in Italy. Established results concerning disparities between the Northern and Southern regions of Italy hold up when adjusting incomes for the regional purchasing power. Poverty is still concentrated in the Southern part of the country. Furthermore, the cost-of-living indices that have the highest impact on the Italian income distribution are those accounting for regional differential in housing prices.
\end{abstract}

Keywords: Income Distribution, Regional Purchasing Power Parity, Italy

\section{Introduction}

Adjusting for differences in relative price levels is widely recognized as being important in inter-country income comparisons. Analogously, intra-country com- parisons should be adjusted for sub-national purchasing power parities (PPP). Regional cost-of-living ${ }^{1}$ adjust- ments affect real wages and public transfers and, to a larger extent, income distribution, poverty and inequality within a country. Nevertheless, PPP estimates require detailed price data which are not usually available at subnational level. Spatial price variability has been investigated in developing countries, where regional price differences are expected to be wide because of high degrees of market segmentation (e.g. Coondoo et al., 2004; Jolliffe et al., 2004; Gong and Meng, 2008), and relatively few attempts provide evidence for developed countries. For instance, poverty measures adjusted for cost of living differences in US metropolitan and nonmetropolitan areas show a complete reversal of the nonmetro/metro original poverty profile (Jolliffe, 2006). Kosfeld and Eckey (2008) estimated consumer price index (CPI) and housing rent index (HRI) for German NUTS sub-national areas to analyze price disparities aross German regions. The authors found that disparities of regional per capita GDP adjusted for PPP reduced but did not eliminate East/West real income gap. Adjustment for regional cost of living of poverty rates in the United Kingdom, induced higher value of poverty in Greater London, South

\footnotetext{
${ }^{\mathbf{1}}$ Even if PPP and regional cost-of-living are not technically the same, we use these terms interchangeably in this context.
}

East, Scotland and Northern Ireland and smaller values in the North and in Yorkshire and Humberside (Borooah et al., 1996). Using regional price indices recently provided by Italian National Institute of Statistics (ISTAT) and by Bank of Italy, this paper checks whether the well-known income disparity between Northern and Southern Italy persists after accounting for regional price differentials. The next section describes the spatial price indices estimated for Italian regions. Section 3 reports the main effects of cost of living adjustment on household disposable income, inequality and poverty. Section 4 concludes.

\section{Data}

ISTAT in collaboration with Institute Guglielmo Tagliacarne--Union of Italian Chambers of Commerce (Istat, 2008) estimated spatial price indices for Italian regions' capital cities ${ }^{2}$ in 2006. Three expenditure items were selected: Food, Clothing \& Footwear and Furniture \& Furnishings. Based on these indices, Bank of Italy (Cannari and Iuzzolino, 2009) first estimated regional price indices for other consumption categories, and then aggregated all the commodity--group prices into regional cost--of--living indices. Based on alternative hypotheses, which essentially refer to the estimation procedure of additional commodity--group indices and to the weights attached to each item in the aggregation procedure, Bank of Italy finally estimated twelve purchasing power pari-

${ }^{2}$ Italian regions are administrative units that correspond to the second level of disaggregation in the Eurostat Nomenclature of the Territorial Units for Statistics, named NUTS2. 
ties.

To examine the sensitivity of income distribution to the choice of geographical cost--of--living indices, we selected three out of twelve cost--of--living indices ${ }^{3}$ (Table 1). Index $P P P_{1}$ assumes spatial price variation only for prices related to Food, Clothing \& Footwear and Furniture \& Furnishings, holding spatial prices of all other goods and services fixed. This index refers only to survey data collected by ISTAT and to consumption categories representative of about one third of the Italian households' consumption budget. Index $P P P_{2}$ shares the same hypothesis of $P P P_{1}$ but incorporates also an index of house prices provided by Italian Housing Market Agency as a proxy of price variability of housing costs. Regional prices of all other items are assumed not to vary. Index $P P P_{9}$, instead, uses actual and imputed rents provided by Bank of Italy's Survey of Household Income and Wealth (SHIW) for housing costs. Moreover, index $P P P_{9}$ includes regional price variation also for Health, Maintenance \& Repairs and Other commodities and services, using data released by the Italian Ministry of Economic Development. In order not to overestimate the South/North-Center gap, quality differences in both housing costs and expenditure services are controlled for. The remained items, which account for $22 \%$ of the Italian average consumption's budget, are assumed fixed. Regardless of the estimation procedure, housing prices represent the major element of variation, accounting for almost $70 \%$ of cost--of--living differences between Northern and Southern Italy. It should be noted that Bank of Italy estimation of housing costs, via home property values or via actual and imputed rents, takes into account differences in internal characteristics of houses (like number of bathrooms, size, typology, etc.) but it does not control for external characteristics (like neighborhood socio-economic characteristics, safety, quality of services, infrastructures, etc.). Therefore, housing cost differentials may reflect local characteristics, and, more generally, quality of life differences across regions. We selected different price indices since there is still a debate whether to include housing costs in regional income comparisons (see Siminiski and Saunders, 2004, for a discussion).

Income data are from 2006 SHIW. We use annual disposable income of all household members, which is the sum of wages and salaries, income from self-employment, pensions, public assistance, private transfers, income from real properties, imputed rental income from owner-occupied dwellings, and yields on financial assets net of interest paid on mortgages, net of tax and social security transfers. Household is defined as a group of

${ }^{3}$ Subscripts refer to column's number in Table A2.1 in Cannari and Iuzzolino, 2009, pp.33-34.
Table 1. Estimated regional cost--of--living indices in 2006.

\begin{tabular}{|c|c|c|c|}
\hline Regions/Areas & $P P P_{1}$ & $P P P_{2}$ & $P P P_{9}$ \\
\hline Piemonte & 100.7 & 100.7 & 105.1 \\
\hline Valle d'Aosta & 101.2 & 112.7 & 106.4 \\
\hline Lombardia & 103.4 & 109.5 & 114.1 \\
\hline Liguria & 101.9 & 120.8 & 112.9 \\
\hline North West & 101.8 & 110.7 & 109.6 \\
\hline Trentino Alto Adige & 103.0 & 119.2 & 112.3 \\
\hline Veneto & 101.4 & 102.9 & 101.0 \\
\hline Friuli Venezia Giulia & 102.1 & 98.5 & 106.9 \\
\hline Emilia-Romagna & 101.5 & 109.8 & 108.9 \\
\hline North East & 102.0 & 107.3 & 107.2 \\
\hline Toscana & 99.8 & 112.9 & 111.8 \\
\hline Umbria & 100.1 & 96.3 & 106.5 \\
\hline Marche & 99.8 & 100.7 & 96.9 \\
\hline Lazio & 100.0 & 119.1 & 112.4 \\
\hline Center & 99.9 & 106.9 & 106.7 \\
\hline Abruzzo & 99.1 & 92.2 & 92.6 \\
\hline Molise & 96.7 & 82.9 & 85.1 \\
\hline Campania & 96.6 & 100.2 & 91.5 \\
\hline Puglia & 98.2 & 90.9 & 91.9 \\
\hline Basilicata & 98.5 & 82.1 & 85.1 \\
\hline Calabria & 99.1 & 81.9 & 85.2 \\
\hline Sicilia & 97.9 & 88.4 & 92.8 \\
\hline Sardegna & 99.4 & 92.9 & 90.7 \\
\hline Southern Italy & 98.2 & 88.7 & 89.3 \\
\hline North-Center & 101.2 & 108.3 & 107.8 \\
\hline Italy & 100.0 & 100.0 & 100.0 \\
\hline South/North-Center & 97.0 & 82.0 & 82.8 \\
\hline
\end{tabular}

Source: Cannari and Iuzzolino, Bank of Italy 2009.

individuals living together who, independently of their kinship, share their income wholly or in part. To take into account household composition, incomes are adjusted by an equivalence scale. We use the OECD- modified scale (Hagenaars, 1994) which assigns a value of 1 to the household head, a value of 0.5 to each additional adult member and a value of 0.3 to each child under the age of 15 . 


\section{Effects of Regional Cost--of--Living on Income Distribution}

Table 2 provides summary measures for household incomes in 2006, both in nominal terms (second column) and in PPP terms (third to fifth columns). Regardless of PPP's definition, household income adjusted for cost--of--living differences is, on average, lower than actual income. Concentration decreases, narrowing the gap between rich and poor households, mainly due to a reduction of the ratio between median and first decile. Discrepancies are more clear-cut when housing related costs are considered. For instance, the Gini coefficient is $31.62 \%$ for nominal incomes and equal to $31.30 \%$ for incomes adjusted with $P P P_{1}$. For income deflated by $P P P_{2}$ and $P P P_{9}$ Gini coefficients are instead 30.36\% and $30.20 \%$, respectively, corresponding to a reduction of $4.5 \%$. There are negligible differences between incomes deflated by $P P P_{2}$ and by $P P P_{9}$, suggesting, on one hand, that the inclusion of other goods and services price estimates does not alter the variability of regional cost-of-living and, on the other hand, that results are robust to different housing price estimation procedures. Note that the PPP-adjusted summary measures reported in Table 2 and those computed on nominal income are all significantly different ${ }^{4}$.

Income is adjusted with the OECD-modified equivalence scale. difference significant at $1 \%$ level. difference significant at $5 \%$ level.

To detect magnitude and sign of distributional changes,

Table 2. Summary measures of household income distribution.

\begin{tabular}{|c|c|c|c|c|c|c|c|}
\hline \multirow[b]{3}{*}{$\begin{array}{l}\text { Mean } \\
\text { (euro) }\end{array}$} & \multirow{3}{*}{$\begin{array}{c}\text { Nominal } \\
\text { income } \\
18,970\end{array}$} & \multicolumn{6}{|c|}{ Income deflated by } \\
\hline & & \multicolumn{2}{|c|}{$P P P_{1}$} & \multicolumn{2}{|c|}{$P P P_{2}$} & \multicolumn{2}{|c|}{$P P P_{9}$} \\
\hline & & 18,839 & $(* *)$ & 18,166 & $(* *)$ & 18,152 & $(* *)$ \\
\hline $\begin{array}{l}\text { Median } \\
\text { (euro) }\end{array}$ & 16,224 & 16,134 & $(*)$ & 15,674 & $(* *)$ & 15,607 & $(* *)$ \\
\hline Gini (\%) & 31.62 & 31.30 & $(* *)$ & 30.36 & $(* *)$ & 30.20 & $(* *)$ \\
\hline $\begin{array}{l}\text { Theil } \\
\text { (\%) }\end{array}$ & 19.96 & 19.64 & $(* *)$ & 18.80 & $(* *)$ & 18.73 & $(* *)$ \\
\hline P9010 & 4.08 & 4.00 & $(* *)$ & 3.70 & $(* *)$ & 3.69 & $(* *)$ \\
\hline P9050 & 1.95 & 1.93 & $(*)$ & 1.89 & $(* *)$ & 1.89 & $(* *)$ \\
\hline$P 5010$ & 2.09 & 2.07 & $(*)$ & 1.96 & $(* *)$ & 1.95 & $(* *)$ \\
\hline
\end{tabular}

Note: authors' calculation on weighted household income data from 2006 SHIW.

\footnotetext{
${ }^{4}$ We assessed the significance of the differences with paired difference tests. In case of complex non-linear statistics, such as the Gini coefficient, we used a bootstrap procedure with 500 draws. For details see Longford et al., 2010.
}

we made use of the relative distribution method (Handcock and Morris, 1999), which focuses on the comparison between two income distributions, one chosen as baseline (reference) and the other as comparison. Our baseline distribution is the nominal income distribution. The baseline distribution is partitioned in quantiles ${ }^{5}$. The comparison distribution is the PPP--adjusted income distribution. The relative distribution is simply given by the the ratio of the percentage of households in the comparison distribution to the percentage of households in the baseline income distribution in each baseline decile. When the percentage of households in a decile is higher (lower) than the percentage in the reference distribution, the relative distribution will be higher (lower) than one. When there is no change, the relative distribution will be flat at the value of 1 . To put it another way, the probability of being in correspondence of a decile of the reference distribution is higher (lower) for households belonging to the comparison population. Figure 1 reports the relative densities of the income distributions in PPP terms compared to the nominal income distribution. ${ }^{6}$

When we consider income distribution deflated by $P P P_{1}$ as comparison distribution (panel (a)) there is a slight gathering of the relative density toward the median, reflecting an increase of the mass of the comparison distribution in the middle classes and a corresponding decrease at both tails, with respect to the income distribution not adjusted. However, overall differences between the two distributions are slightly noticeable.

On the contrary, when we compare income distribution adjusted for $\mathrm{PPP}_{2}$ to income distribution in nominal terms (panel (b)) we observe a huge increase of the mass of the distribution between first and fourth income decile and, to a lesser extent, between fifth and sixth, counterbalanced by a sizable reduction at the bottom decile and, especially, at the top of the distribution. The same conclusions, besides a slight raise between fourth and fifth decile, not previously recorded, are reached when using $P P P_{9}$ (panel (c)). As an example, the percentage of households whose $P P P_{1}$--adjusted income falls between the third and fourth deciles of the nominal income distribution is $7 \%$ higher than the corresponding share in the reference distribution, while it is $19 \%$ higher when we compare the $P P P_{9}$--adjusted income distribution to the nominal income distribution. On the contrary, 9.6\% of households whose income is $P P P_{1}$--adjusted falls in the top income decile of the nominal income distribution, and this percentage falls to $7.6 \%$ when income distribution is deflated by $P P P_{9}$.

\footnotetext{
${ }^{5}$ The distribution can be broken into any number of quantiles. Here we adopted the decile breakdown.

${ }^{6}$ The continuous dotted line is estimated with a nonparametric regression. See Massari et al. (2009) for a recent application of relative density on income distribution.
} 

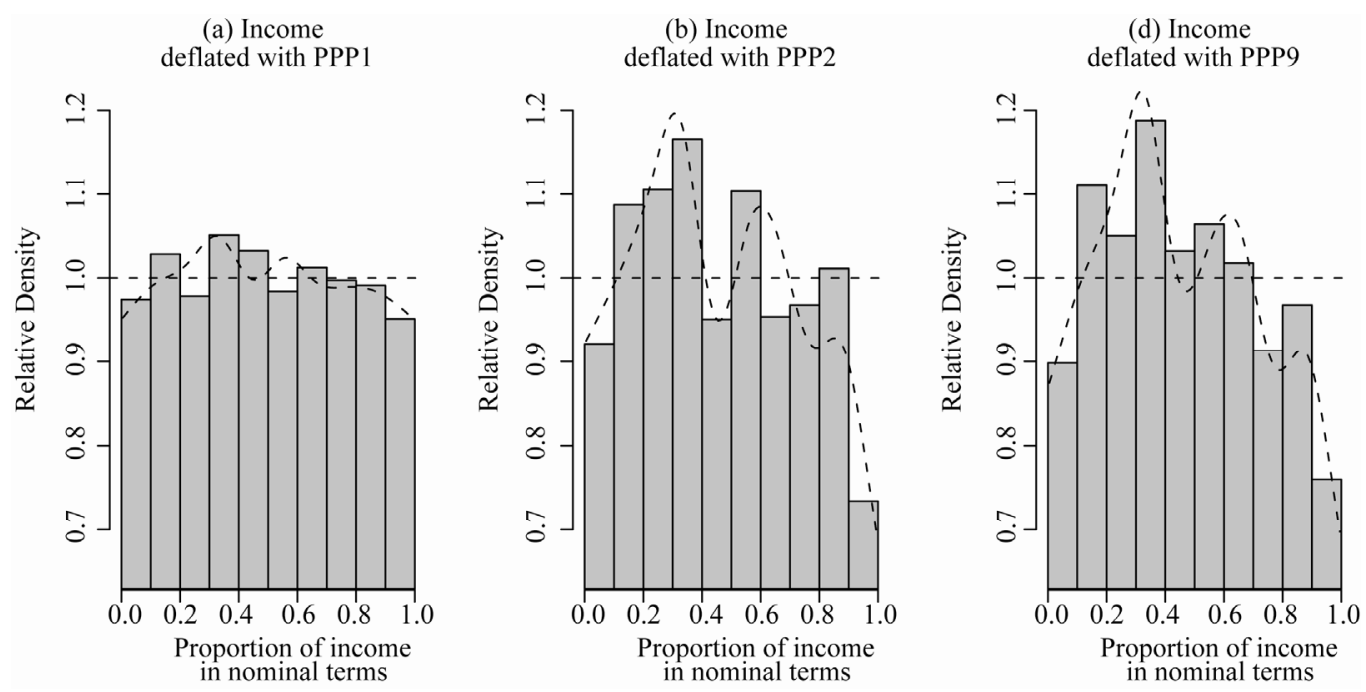

Figure 1. Relative distribution. The y-axis measures the relative fraction of households ranked by PPP adjusted income distributions that falls in each nominal income distribution decile.

To observe what happens in terms of inequality and poverty between and within Italian regions before and after price-adjustment, we consider only $P P P_{1}$ and $P P P_{9}$, since the results obtained with $P P P_{2}$ largely overlap those achieved with $P P P_{9}$.

First, the decomposition of Theil index into between-region and within-region, reported in Table 3, reveals a significant reduction in the between-region component when PPP-adjusted income is accounted for. Thus, since the within-region component remains stable ${ }^{6}$ the percentage contribution of the between-region component drops from $14.4 \%$ for nominal income to $8.1 \%$ for income $P P P_{9}$-adjusted.

The percentage of households at-risk-of-poverty in NUTS1 macro-areas is reported in Table 4. Households at-risk-of-poverty are those below a low-income threshold, which is defined as 60 per cent of the median equivalent income. The overall percentage of households at risk of poverty decreases from $18 \%$ to $15.7 \%$. This reduction is due to a significant decrease of the rate of

Table 3. Decomposition of Theil index between and within regions. Estimated values and percentage contribution.

\begin{tabular}{|c|c|c|c|c|c|}
\hline Income & Theil & Between & Within & Between & Within \\
\hline & index & component & component & \multicolumn{2}{|c|}{$\%$ contribution } \\
\hline Nominal & 19.96 & 2.88 & 17.08 & 14.4 & 85.6 \\
\hline $\begin{array}{c}P P P_{1}^{-} \\
\text {deflated }\end{array}$ & 19.64 & 2.55 & 17.09 & 13.0 & 87.0 \\
\hline $\begin{array}{c}\mathrm{PPP}_{9}^{-} \\
\text {deflated }\end{array}$ & 18.73 & 1.51 & 17.22 & 8.1 & 91.9 \\
\hline
\end{tabular}

${ }^{6}$ Small differences in the within-regions component are due to small changes in the income shares of the regions used as weights in computing the component. poverty in Southern Italy (South and Islands) which is not fully counterbalanced by households at-risk-of-poverty in North-West and Central Italy. After adjusting for $\mathrm{PPP}_{9}$, however, households at-risk-of-poverty are still concentrated in Southern Italy (almost 60\% with respect to $68 \%$ in the nominal scale).

We now analyze how mean income changes in each region when income is deflated by $P P P_{1}$ (Figure 2(a)) or by $P_{9}$ (Figure 2(b)). The magnitude of percentage changes is displayed with varying degree of gray. The lighter (darker) the color, the higher is the increase (decrease) of regional mean income after controlling for regional PPP's. The evidence in Figure 2(a) is rather mixed, with positive changes mainly concentrated in the Southern Italy, but with different degrees. Only Campania and Molise experience a percentage change higher than 3\%. In the North-Central Italy, Tuscany and Marche display positive changes of mean income, while for the remaining regions we observe a decrease of the mean, which ranges to very low values (Umbria and Lazio), to a reduction of $3 \%$ in Lombardy.

Results are more definite in Figure 2(b), with a polarization between Southern regions which display an increase higher than 3\%, and North-Central regions that experience a decline in mean income of over $3 \%$, with the exception of Veneto $(-1 \%)$.

Finally, Figure 3 reports the relative distribution of households living in North-Central Italy (comparison distribution) with respect to the distribution of those living in Southern Italy (reference distribution), according to different deflation adjustments. The gap between North-Central and Southern Italy reduces, after adjusting with $P P P_{9}$, but remains wide. For a household living in North-Central Italy the probability of falling between 
Table 4. Households at-risk-of-poverty in NUTS1 regions. Percentage values and percentage contribution.

\begin{tabular}{|c|c|c|c|c|c|c|}
\hline \multirow[t]{2}{*}{ Income } & \multicolumn{5}{|c|}{ NUTS1 regions } & \multirow[t]{2}{*}{ Italy } \\
\hline & North-West & North-East & Center & South & Islands & \\
\hline Nominal & 6.73 & 9.47 & 9.75 & 38.67 & 38.50 & 18.00 \\
\hline$P P P_{1}$-deflated & 7.00 & 9.76 & 9.62 & 36.46 & 36.57 & 17.43 \\
\hline$P P P_{9}$-deflated & 8.85 & 8.95 & 11.06 & 28.90 & 29.72 & 15.74 \\
\hline \multicolumn{7}{|c|}{ percentage contribution to aggregate poverty } \\
\hline Nominal & 10.37 & 10.87 & 10.81 & 46.89 & 21.07 & 100.00 \\
\hline$P P P_{1}$-deflated & 11.15 & 11.56 & 11.01 & 45.63 & 20.65 & 100.00 \\
\hline$P P P_{9}$-deflated & 15.60 & 11.73 & 14.02 & 40.06 & 18.59 & 100.00 \\
\hline
\end{tabular}

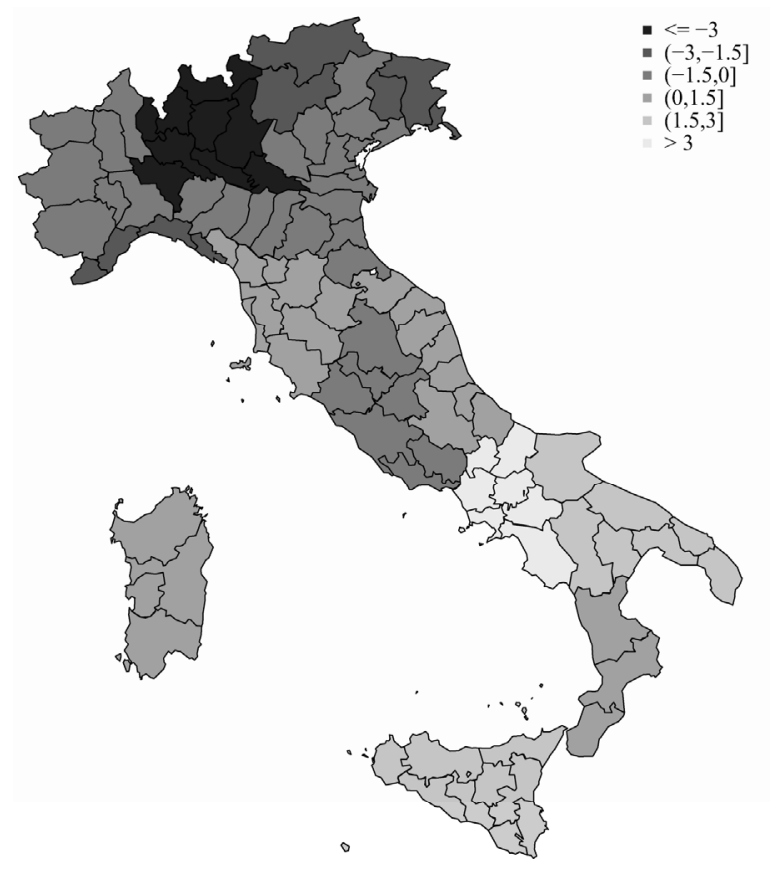

(a)

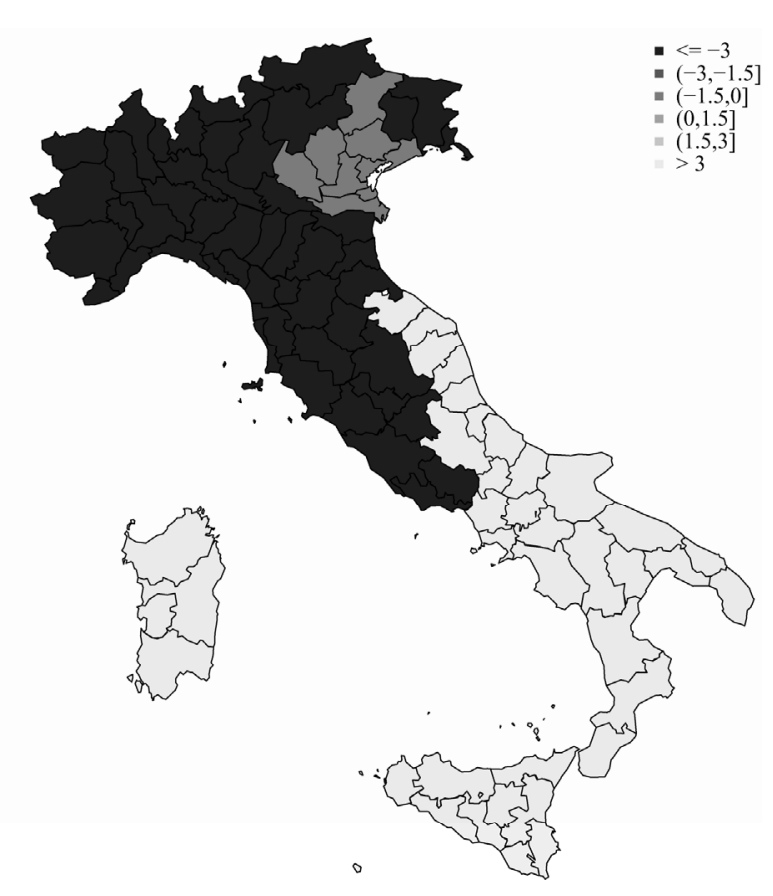

(b)

Figure 2. Percentage changes of the regional mean income between the income distribution deflated by $P P P_{1}(a)$, and by $P P P_{9}$ (b) and the income distribution in nominal terms.

sixth and tenth decile of the income distribution of the South is much higher than that of the corresponding household in the reference population. The reduction of the gap between the two areas is mainly due to a decrease in the mass in the top income class. Indeed, a household in the top income decile of the nominal income distribution has a probability more than three times higher to live in North-Center than in Southern Italy. This probability is "only" two times higher, when $P P P_{9}$-adjusted income distribution is considered. In addition, there is a slight increase of the density between sixth and eighth decile. Hence, the shrinkage of the gap between South and North-Center is mainly due to a loss in terms of purchasing power incurred by richer households, while for households just above the median there is a modest, but significant, widening of the gap.

\section{Concluding Remarks}

Overall, the distribution of household income is "reshuffled", after controlling for the purchasing power of households residents in different regions. Higher income 

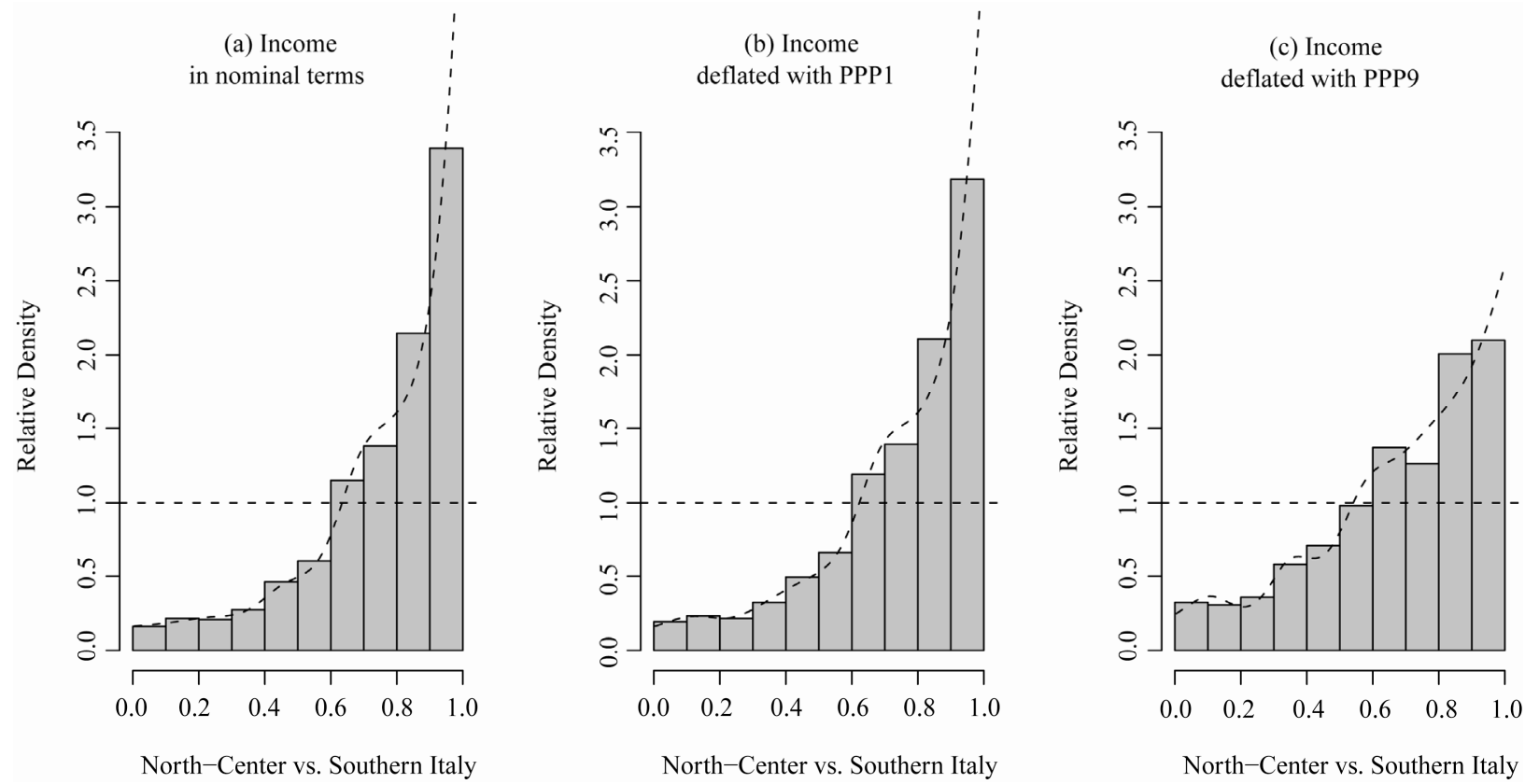

Figure 3. Relative distribution. The y-axis measures the relative fraction of households living in North-Central Italy that falls in each Southern Italy income decile, according to different deflation adjustments.

regions tend to be higher price level regions, therefore inequality between regions and overall inequality across households reduces after adjusting for prices. The apparent living standards of households living in the South improve when the regional price index is used, but only when housing price variations are included in the index. Despite this, poverty is still concentrated in the South whichever regional price index is used. An issue left for further research regards the relationship between quality of life and cost-of-living. Had housing costs been positively correlated with quality of life, the gain in terms of purchasing power experienced by households living in poorer areas, where housing prices are typically lower, could be interpreted as a compensation for the loss in terms of quality of life.

\section{Acknowledgments}

we would like to thank an anonymous referee for helpful comments.

\section{Reference}

[1] Borooah V. K, Gregor P. P. M., Kee P. M. M., Mulholland G.E., (1996). Cost--of--living differences between the regions of the United Kingdom, in J. Hills (Ed.), New Inequalities, the changing distribution of income and wealth in the United Kingdom, Cambridge University Press.

[2] Cannari L., Iuzzolino G., (2009). Le differenze nel livello dei prezzi al consumo tra Nord e Sud, Questioni di Eco- nomia e Finanza, Banca d’Italia.

[3] Coondoo D., Majumder A., Ray R., (2004). A Method of Calculating Regional Consumer Price Differentials with Illustrative Evidence from India, Review of Income and Wealth, 50(1), 51-68.

[4] Gong, C.H., Meng X., (2008). Regional Price Differences in Urban China 1986-2001: Estimation and Implication, IZA Discussion Papers, n.3621.

[5] Hagenaars A. J. M., K. De Vos and M. A. Zaidi (1994). Poverty Statistics in the Late 1980s: Research Based on Micro-Data, Office for Official Publications of the European Communities. Luxembourg.

[6] Handcock M. S., Morris M., (1999). Relative distribution methods in the social sciences, Cambridge University Press.

[7] Istat (2008). Le differenze nel livello dei prezzi tra i capoluoghi delle regioni italiane per alcune tipologie di beni, Istat, Roma.

[8] Jolliffe D., (2006), Poverty, Prices, and Place: How Sensitive is the Spatial Distribution of Poverty to Cost of Living Adjustments?, Economic Inquiry, 44(2), 296-310.

[9] Jolliffe D., Datt G., Sharma M., (2004), Robust Poverty and Inequality Measurement in Egypt: Correcting for Spatial-price Variation and Sample Design Effects, Review of Development Economics, 8(4), 557-572

[10] Kosfeld R., Eckey H.F., (2008). Market Access, Regional Price Level and Wage Disparities: The German Case, MAGKS Papers on Economics, Philipps-Universitt Marburg.

[11] Longford N. T., M. G. Pittau, R. Zelli and Riccardo Massari (2010). Measures of poverty and inequality in the countries and regions of EU, ECINEQ Working Papers 
182, Society for the Study of Economic Inequality.

[12] Massari R., M. G. Pittau and R. Zelli (2009). A dwindling middle class? Italian evidence in the 2000s. Journal of Economic Inequality, 7(4), pages 333-350.
[13] Siminski P. and P. Saunders (2004). Accounting for Housing Costs in Regional Income Comparisons. Australasian Journal of Regional Studies 10(2), 139-156. 